\title{
Systematic Review \\ Aromachology and Customer Behavior in Retail Stores: A Systematic Review
}

\author{
Davide Giacalone $^{1, *(\mathbb{D})}$, Bartłomiej Pierański ${ }^{2}$ and Barbara Borusiak ${ }^{2}$ (i) \\ 1 Department of Technology and Innovation, University of Southern Denmark, Campusvej 55, \\ 5230 Odense M, Denmark \\ 2 Department of Commerce and Marketing, Poznan University of Economics and Business, Al. Niepodległości \\ 10, 61-875 Poznan, Poland; bartlomiej.pieranski@ue.poznan.pl (B.P.); barbara.borusiak@ue.poznan.pl (B.B.) \\ * Correspondence: dg@iti.sdu.dk
}

check for updates

Citation: Giacalone, D.; Pierański, B.; Borusiak, B. Aromachology and Customer Behavior in Retail Stores: A Systematic Review. Appl. Sci. 2021, 11, 6195. https://doi.org/10.3390/ app11136195

Academic Editor: Maurizio Faccio

Received: 4 May 2021

Accepted: 28 June 2021

Published: 3 July 2021

Publisher's Note: MDPI stays neutral with regard to jurisdictional claims in published maps and institutional affiliations.

Copyright: (c) 2021 by the authors. Licensee MDPI, Basel, Switzerland. This article is an open access article distributed under the terms and conditions of the Creative Commons Attribution (CC BY) license (https:/ / creativecommons.org/licenses/by/ $4.0 /)$.

\begin{abstract}
Interest in the use of scents in retail environments for creating better customer experiences is growing. Yet, knowledge of the effectiveness of aromachology to affect actual customer behavior and ultimately increase turnover is incomplete, as published results present inconsistencies and are often based on highly controlled environments rather than actual store environments. Situated within this context, this paper offers a systematic review on research in aromachology with a focus on effects on actual customer behavior in actual retail environments. As expected, the available research on actual environments (relative to laboratory-based studies) is limited, with only 20 articles meeting the inclusion criteria. While reported results are, overall, indicative of the positive effects of scent on customers' emotional states and on their in-store behavior (dwell time, product choices) and attitudes (purchase intention, intention to revisit), several critical issues with the available literature emerged. These pertain primarily to a lack of sufficient methodological details (specifically on the scents, their compositions, intensity and methods of delivery), a narrow focus on scents without considering interactions with other atmospherics factors, and a general disregard of individual differences in olfaction. The review provides suggestions for addressing these shortcomings and improving the quality and actionability of this line of research.
\end{abstract}

Keywords: aromachology; scent marketing; retailing; customer behavior

\section{Introduction}

For centuries, scents have been used for religious purposes, in traditional treatments as well as in everyday life. From the very beginning of civilization, people realized that scents regarded as pleasant may have a good influence on their mood, health, and their social position perception [1]. Nowadays, scents are also widely used for business purposes and have become an interesting field of study focusing on factors influencing consumer behavior and well-being [2-4]. This, to a large extent, is a result of the growing interest in environmental psychology, which deals with interrelationships between individuals and their physical settings, and the way individual behaviors and experiences are affected by environmental factors [5]. An often applied approach to examine the impact of the environment on people experiences is Stimulus-Organism-Response model, which emerged in the middle of 1960s [6]. It was developed later by Mehrabian and Russell [7], who focused on three dimensions expressing the emotional state of an individual (pleasure, arousal and dominance), which results in approach or avoidance responses. That model received a lot of attention from researchers as a promising method to detect how to induce a desirable behavior in people by design of environmental settings [8]. Both service and retail companies are highly interested in creating strong and appealing in-store experiences, and the use of scents is, in this context, generally regarded as a potential source of competitive advantage [9]: for example, scents may be used to differentiate the brand in an increasingly competitive market where the usual marketing mix is not sufficient (an example being 
major clothing chains such as Abercrombie \& Fitch and hotel companies such as Marriot being noted for their signature scents), as well as generally to provide better in-store experiences to their customers and increase their spending and likelihood of revisiting the store.

The customer experience is a complex construct mainly because it is affected by numerous elements, only some of which are controlled by the retailer. It is based on the set of interactions between a customer and a product or/and a company and also between a customer and other customers, which generate a reaction [10-12]. Schmitt [13] distinguishes five types of experiences: sensory (sense), affective (feel), cognitive (think), physical (act), and social-identity (relate). Sensory experience is created by the retail outlet atmosphere (referred to as "atmospherics" and regarded as a marketing tool), which is based on the sensory channels: sight, sound, touch, and smell [14]. Additionally, the current concept of retail atmospherics-design-ambient-social-trialability (DAST) - acknowledges odors as an important ambient factor and potentially powerful instrument used for customer experience building [15].

The term "aromachology" first appeared in 1982 to denote the science that is dedicated to the study of the relationship between psychology and scents to elicit a variety of specific emotions, such as relaxation, exhilaration, sensuality, happiness and well-being. Indeed, the sense of smell is considered to be the one most closely related to emotional reactions, as the olfactory bulb is directly connected to the areas of the brain (collectively known as the limbic system) that deal with emotion and memory [16,17]. Moreover, the sense of smell is emotionally processed and, unlike other sensory modalities, does not require consciously attending to any stimulus and instead exerts emotional consequences without conscious perception of the odor itself $[18,19]$. Due to these characteristics, interest in the use of scents to affect human behavior has been steadily increasingly [4,20]. In recent years, several studies have been published concerning usage of aromas in a retail environment (shops, restaurants, etc.), and interest in aromachology (as well as retail atmospherics more generally) has been steadily increasing [2-4,20,21].

Historically, the majority of studies who have sought to explain the effect of scents on customer behavior have considered one or both of the following two theoretical frameworks:

1. The already mentioned Stimulus-Organism-Response (S-O-R) paradigm $[1,7,22]$, in which scents generate affective and cognitive responses in consumers (e.g., pleasantness, arousal), which, in turn, affect approach or avoidance behaviors towards products. From an applied perspective, if retailers introduce a positively valenced scent, customers' experience with the store, dwelling time and ultimately purchases will be enhanced;

2. A thematic congruency theory [23-25] proposing that the effect of scents on behavior depends on their perceived congruency with their target product; in this framework, scents can become a signal or facilitator for drawing attention towards specific products, meaning that when there is a match between the product and the scent, an effect can be expected.

It is apparent and should be emphasized that these theories are not mutually exclusive. Schifferstein and Blok [26] explain this with anecdotal example, involving the smell of freshly baked bread, which both gives consumers a pleasant experience (fresh bread smells good), but it also communicates information about the presence and the characteristics of the products, for example, it signals that the bread is fresh and probably still warm. This means that the smell of bread can have consequences for customer behavior in general and for the behavior towards the focal product (bread) and related products (e.g., bakery items).

The available literature offers some degree of support for both theories. Several of the available studies reported positive effects of scent applied in a shop on customers' emotional states and on their in-store behavior, measured in terms of dwell time and product choices [27], as well as on stated attitudes such as purchase intention and likelihood to revisit the store $[2,28]$. Some studies also suggested that scent may influence the amount of money spent [2], although other studies indicated that this relationship may be more 
complex. For instance, Herrmann and collaborators [29] found that a simple scent increased actual spending, whereas a more complex scent had no such effect. Such effects are often moderated by the congruency of the scent with the object, in accordance with the second theory [30].

Nevertheless, several "null" results have also been reported (e.g., [26]). This is possibly due to differences in the type of product and environments considered, as well as in variation in methodological aspects-for example, the intensity of the scent and whether it was consciously experienced or not, which is very important because the emotional effects of odors are different depending on whether or not they are consciously perceived [18]. Moreover, according to some (e.g., [31]), in a retail context the ambient scent could have negative effects if they were perceived by consumers as a marketing tool to influence their behavior (at least in absence of elements justifying the presence of that smell). These inconsistencies in the results, however, suggest that the knowledge of the effects of aromachology in retailing is still incomplete.

While promising findings have sparked interest in the use of scents in retail environments, much (most) of the available literature is based on studies conducted in controlled settings, such as laboratories or simulated environments (e.g., [30]), and/or is based on attitudinal data such as product and store evaluations (e.g., [32-34]). It is therefore uncertain how much of these findings correspond to actual behaviors in actual retail environments.

Against this backdrop, the present paper presents a systematic review of the literature on aromachology with a focus on customer behavior in actual retail environments. The main research question this review seeks to answer is, therefore, the following: "what is the evidence for aromachology effects on actual customer behavior in actual retail environments?" To the best of the authors' knowledge, this is the first review paper to do so in a systematic way. The main contribution of the paper is threefold: first, to summarize the available evidence on the topic, secondly, to critically evaluate the available literature, and, finally, to provide recommendations for future research on aromachology.

\section{Methods}

Since this review focuses on the application of aromachology in retailing and its effects on consumer behavior, the main inclusion criteria were that studies should present experimental data on ambient scents of retail areas and include at least one behavioral variable. By contrast, studies were excluded if (1) they were not based in actual retail environments (e.g., exclusively lab-based studies or using mock-ups and simulated environments), (2) they focused on food products, (3) they focused on scents originating from the product itself rather than the environment (e.g., [17]), (4) focused on the general experience of the retail environment but did not include any behavioral variables, and finally (5) if they did not include any experimental data (e.g., reviews, editorials, etc.). The reason for excluding food-related studies was twofold: first, because the use of scents on food-related behavior has received more attention in the literature, especially in the context of how to use to scents to direct consumers towards making healthier choices, and secondly because using scents in food establishments presents some specific technical issues (e.g., safety/hygiene regulations, interaction between ambient scents and odors originating from food items), which are not necessarily shared by other retail environments. Readers interested in applications of aromachology in food stores are directed to the review paper by Girona-Ruiz and collaborators also appearing in this special issue [35].

The protocol for the systematic review was informed by the PRISMA guidelines [36] and is shown in Figure 1. A literature search was performed using two databases-Web of Science (Core Collection) and Scopus. The search in the aforementioned databases was performed during April 2021. No time limits were applied to the search itself. Search terms were initially identified by discussion between the authors, and the list was subsequently refined after conducting a preliminary set of scoping searches from the focal databases. Keywords used for the search were retail atmospherics, aroma marketing, ambient scents, consumer behavior, and aromachology using Boolean operators. A wildcard asterisk $\left({ }^{*}\right)$ was 
applied to all word stems in order to retrieve all articles that included terms starting with each word stem. The following Boolean search terms were defined based on the outlined research requirements:

$T S=\left(\left(\right.\right.$ retail atmospheric ${ }^{*}$ OR aroma marketing ${ }^{*}$ OR ambient scent ${ }^{*}$ OR scent ${ }^{*}$ OR aromachology*) AND (consumer* OR customer*)).

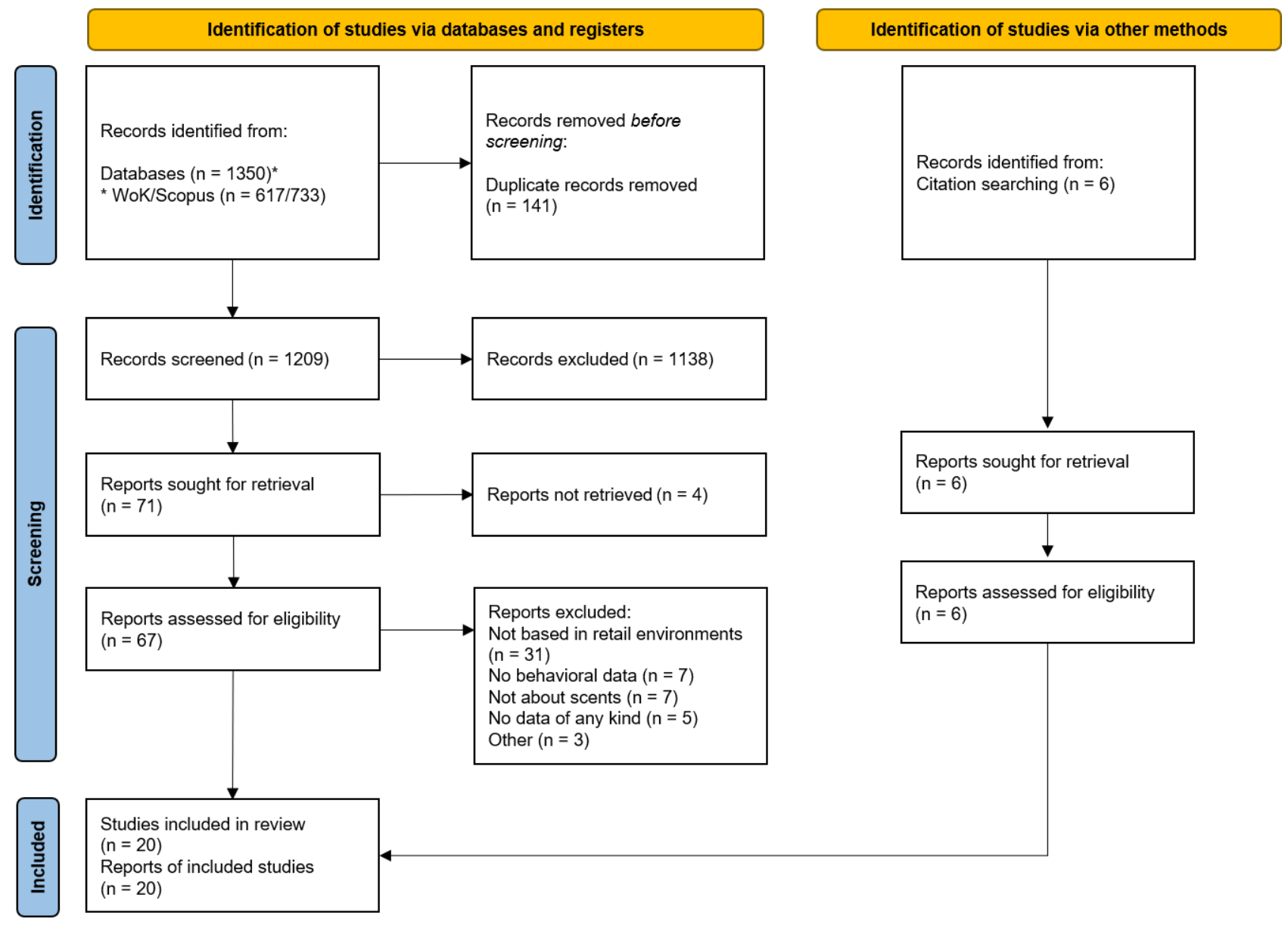

Figure 1. PRISMA flow diagram for the systematic review of aromachology and customer behavior.

The search yielded, respectively, 617 records on Web of Science and 733 records on Scopus. The records came from a wide variety of research fields, with business, management, food science and technology being the fields most represented (Figure 2). The database search further supplemented by a manual search using the "snowballing" method, from which additional six records were found (Figure 1). Complete documentation on this process and the full list of records are available as supplementary materials to this paper.

The initial list was screened and duplicate records were removed. After excluding duplicates, the titles and abstracts of each record were inspected to assess their relevance according to the inclusion criteria. Studies that met the inclusion criteria were analyzed in-depth with a focus on the following theoretical and methodological aspects: type of retail environment, product category, hypotheses and findings, type of scents used and method of delivery in the retail environment, number of subjects and target behavioral variable. 

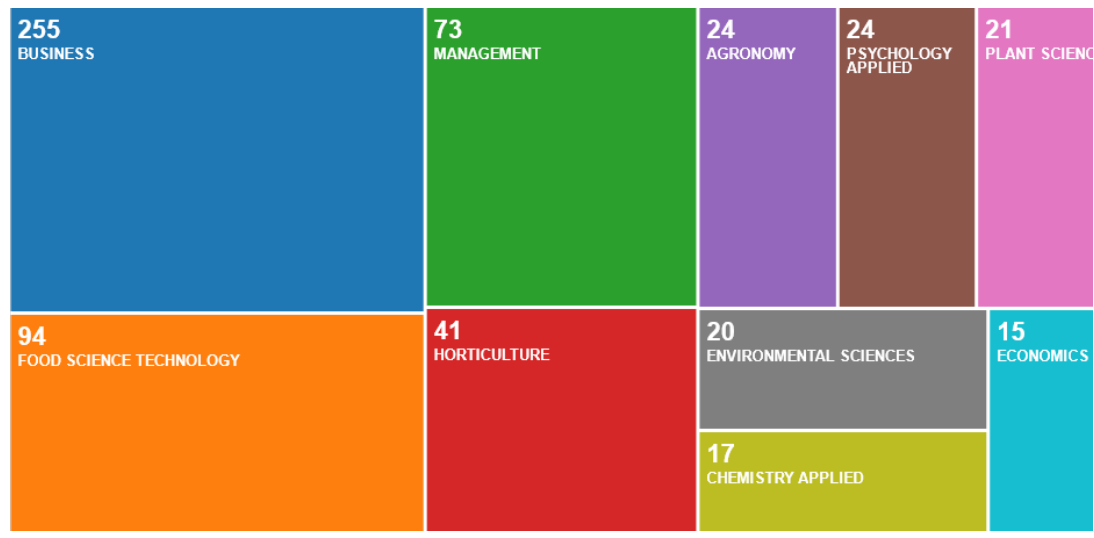

Figure 2. Treemap of literature pertaining to aromachology, showing breakdown by scientific fields ( $\mathrm{N}=617$, Source: Web of Science, Clarivariate Analytics, Core collection, Search terms: see Section 2). Fields with fewer than 15 records were omitted to improve legibility.

\section{Results and Analysis}

\subsection{Overview of Included Literature}

Twenty studies met the inclusion criteria and were included in this review (Table 1). The most common reason for exclusion was that studies were not based on actual retail environments (Figure 1), although it should be mentioned that most papers included laboratory-based assessments in addition to the actual retailing environment (e.g., [27,29]), usually to isolate causal mechanisms and/or to document the perceptual properties of the target odors in controlled conditions. In such cases, only the results involving actual retail environments were included for the in-depth review.

All studies but two [27,37] included a control (without scent) condition, so that the effect of adding a scent could be benchmarked against the usual (odorless) store environment. Regardless of whether or not a control condition was included, most papers tested two distinct scents so as to test the effects of both the mere presence of a scent and its specific characteristics (Table 2). Common outcome measures included attitudinal measures via surveys and behavioral records such as in-store dwelling time and sales figures (Table 1).

Table 1. Overview of the literature included in this review, listed chronologically. ${ }^{1} \mathrm{~S}=$ Sales volume, $\mathrm{T}=\mathrm{Dwell}$ time, $\mathrm{A}=$ Attitude survey, $\mathrm{O}=$ Observations.

\begin{tabular}{llll}
\hline Source & Environment & Target Product & Behavioral Measures ${ }^{1}$ \\
\hline Knasko (1989) [38] & Jewerly store & Jewelry & S, T, O \\
Hirsch (1995) [39] & Casino (gambling area) & Slot machines & S \\
Mattila and Wirtz (2001) [40] & Gift shop & Misc. gift items & S, T, O \\
Schifferstein and Blok & Bookstore & Magazines & S \\
(2002) [26] & Shopping mall & Non-grocery & S \\
Chebat \& Michon (2003) [41] & Fashion store & Clothing & S, T, A \\
Spangenberg et al. (2006) [37] & Electrical store & Household appliances & T, A \\
Ward et al. (2007) [1] & (cookers and laundry area) & Books & S, T \\
Parsons (2009) [24] & Bookstore & Clothing & S, T, A \\
Morrison et al. (2011) [42] & Fashion store & Clothing and Jewelry & A \\
Doucé and Janssens (2013) [43] & Clothing store & Books & S, O \\
Doucé et al. (2013) [44] & Bookstore & Plates, candles, baskets, etc. & S, A \\
Herrman et al. (2013) [29] & Home decor & Plants and flowers & S \\
Jacob et al. (2014) [22] & Florist shop (indoor) & Sportswear & S, T \\
Bouzaabia (2014) [45] & Fashion store & Sunglasses and prescriptions glasses & S \\
Madzharov, Block & Optics store & Childrenswear & S, A \\
Card Morrin (2015) [27] & Fashion store(s) & Furniture and accessories & S, T \\
Helmefalk \& Hultén (2017) [25] & Furnishing store & Tour sales & S, O \\
Berčík et al. (2018) [21] & Travel agency & Menswear & S \\
Errajaa et al. (2020) [47] & Clothing store & Clothing & S, T, A \\
Cao \& Duong (2021) [2] & Fashion store & &
\end{tabular}


Table 2. Experimental conditions in the reviewed literature. N/R = not reported.

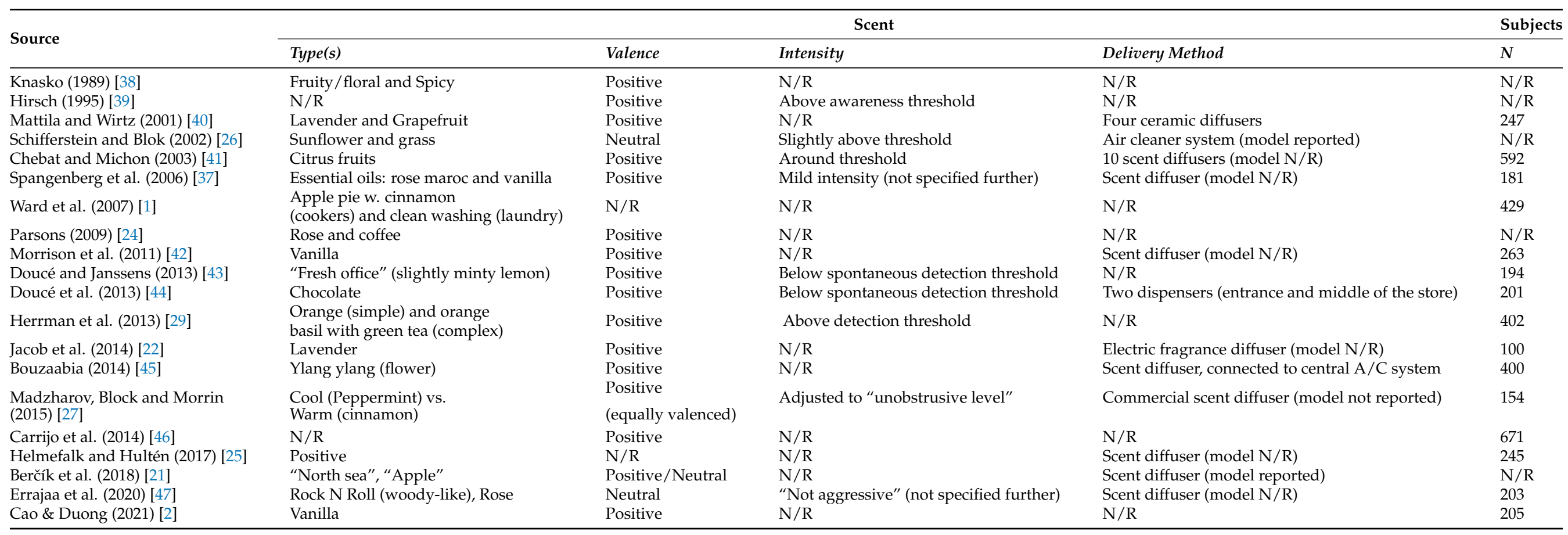




\subsection{Retail Environments and Product Categories}

The included studies covered a rather diverse range of retail stores, showing that scents can affect consumer behavior towards very different product categories. Clothing was the product category most frequently considered in the included literature, which fits expectations as the use of scents is popularly associated with some clothing brands and their stores (e.g., Abercrombie \& Fitch). Other product categories included accessories (e.g., jewelry items, glasses), books and magazines, household appliances, slot machines, and travel packages (Table 1). Accordingly, very different retail environments, ranging from general-purpose stores to specialized ones such as fashion, optics, and book stores. All included studies focused on customer behavior towards tangible goods except for two which focused on, respectively, money gambled on slot machines in a Las Vegas Casino [39], and tour sales in a travel agency [21]. One study [22] was conducted on a florist shop, although it involved a product category (flowers) that naturally emits scents; in that study, the target scent (lavender) was diffused by way of an electric fragrance diffuser, so it met our criterion that scents should originate from the environment and not the product itself.

The duration of the studies, i.e., the time during which scents were diffused in the store, varied significantly among studies, ranging from a few days (e.g., [39]) to several weeks (e.g., [21,26]). Very short time spans pose some problems as customer behavior is known to be affected by a variety of factors, such as weather and time of the day [48,49], which may act as a confounder. Accordingly, most studies included an experimental period of at least one week and/or limited the data collection to a set time of the day.

Finally, all studies but two had an exclusive focus on the effect of scents in a retail environment, and accordingly sought to minimizing variation in other store atmospherics. The two exceptions were two studies which also considered the effect of in-store music and its interactions with scents [40,42].

\subsection{Scent Characteristics and Delivery Methods}

As already mentioned, nearly all studies included some form of pre-test for evaluation of the perceptual properties of the target scents, principally their pleasantness, which was most often assessed via rating scales, and in one case using consumer biometrics (specifically, facial expression analysis [21]). In this regard, it should be noted that all studies used positively or neutrally valanced scents (Table 2). No studies reported using unpleasant scents. This is not surprising and likely due to constraints placed by the store managers who would otherwise be unwilling to participate in the study. A few studies purposefully selected perceptually different, but equally valenced scents in order to investigate whether qualities other than valence may affect customer behavior $([26,39])$. Other perceptual odor characteristics considered during pre-tests were familiarity, intensity, complexity [26,28], as well as conceptual associations such "cool/warm" [27] or "masculine/feminine" [37] (Table 2) to assess congruency with specific products.

Methodological reporting pertaining to the actual scents and methods of delivery is quite poor. Most papers simply mentioned the commercial or lay name for the scent (e.g., "rose", "coffee", "sunflower", see Table 2), but their chemical constituent(s) was rarely reported in the literature. Additionally, while several studies reported whether consumers were consciously aware and/or attended to any ambient scents, the specific intensity of the scent in the retail environment was generally not reported or only qualitatively described with terms such as "mild", "unobstrusive", "not aggressive", etc. No study explicitly considered measuring the concentration of the scent, the airflow conditions, or any other aspects of air quality that may have affected the concentration of the scented particles in the store environments. Likewise, many studies do not mention the device used for diffusing scents but just refer to a generic "dispenser" or "diffuser"; only three studies [21,26,43] mentioned the specific models and/or technical characteristics of the devices (Table 2). Finally, while the store area is usually reported, the number and the positioning of the 
scent unit(s) was rarely given; thus, in many cases, it was not clear whether the scent was perceived throughout the entire store or only close to the target products.

\subsection{Reported Effects on Customers' Behaviors and Theoretical Accounts}

Consistent with the expectations, the vast majority of studies built on the S-O-R and the the mathic congruency theory to explain the effect of scents on behavior often considered both frameworks within the same study. For instance, Doucé et al. [44] studies the effect of adding a chocolate scent on general store behavior (such as length of stay, interaction with the staff, etc.) in a bookstore, which would reflect the S-O-R view, but also the effect on sales for thematically congruent items (cookbooks and romantic novels), which would reflect the thematic congruency theory.

Generally, support for the S-O-R theory seems to be found in the literature at least when it comes to attitudinal outcomes: accordingly, almost all studies included in this review report a positive effect of adding a pleasant scent on, e.g., engagement with the store, satisfaction with the experience, intention to revisit, etc. However, evidence of an effect on actual customer behavior is not always straightforward. For example, Ward [1] found that addition of a pleasant scent made the in-store environment more engaging, but with no differences in actual behavior between scented and control conditions. More to the point, studies that employed two qualitatively different but equally valenced scents reported that only one out of the two actually affected customer behavior, meaning that valence/pleasantness in and of itself is not enough to produce the expected effect on customers' behaviors. For example, Hirsch [39] reported that only one of two scents introduced in a Las Vegas casino increased the amount gambled on slot machines, whereas results for a second scent were not different from the control (no odor) conditions. Similarly, Parsons [24] in a bookstore study found that addition of in-store browsing and sales figures were slightly higher for a congruent scent (coffee) than for an incongruent scent (rose) of equal valence. Finally, Madzharov et al. [27] investigated the effect of adding warm vs. cool scents (equally pleasant) to an optics stores, and found that shoppers were more likely to purchase premium brands and to purchase more items in the warm scent condition. Overall, the literature evidences that valence (pleasantness) is a necessary but not sufficient condition for the effectiveness of scents to affect customer behavior.

This could suggest that other perceptual characteristics of the scents, such as congruency with the product category, are more important in terms of affecting customer behavior. Yet, support for the thematic congruency hypothesis is also limited, with studies reporting mixed results. Perhaps the best support for this theory is in the study on clothing by Spangenberg and collaborators [37], which found a positive impact of adding a "masculine" or "feminine" scent on sales of, respectively, men's and women's clothing items. Douce et al. [44] found that adding a chocolate scent to a bookstore increased buying behavior towards thematically congruents books, but only when controlling for gender (the addition of the scent worked for women but not for men). Schifferstein and Blok [26] investigated whether the degree of thematic congruency between an ambient odor and a magazine affected magazine sales in bookstores by using two odors (a grass odor, congruent with soccer, animal/nature and gardening magazines, and a sunflower odor, congruent with personal care and women's magazines), but found that the ambient scent did not increase sales for thematically congruent magazines, nor did it decrease sales for incongruent magazines. Similarly, Ward and collaborators [1] reported no differences in product-related behavior (e.g., dwelling time) in a different electrical retailer store when a congruent scent was present (vs. a control condition). Schifferstein and Blok [26] explain these inconsistencies by pointing out that it is not enough that a scent is thematically congruent with a product (say, a grass scent with a gardening magazine) to enhance its sales: experience of the association is required on the part of the consumer to effectively pair scents and products. Moreover, even if the scent triggers the intended association with a product, it may not be enough to affect that product's sales, so that ultimately the effect of scents on individual product categories may be rather small [26]. An alternative explanation for the 
lack of support for the thematic congruency theory is that the presence of a pleasant smell may distract customers from their specific shopping goals towards enjoying the overall shopping experience (in accordance with the tenet of S-O-R theory). This explanation is supported by the results of Doucé and collaborators [44], who found that addiction of a chocolate scent in a bookstore increased the general approach behavior but not goaldirected behavior (general books sales increased, but sales of thematically congruent book genres, such as cookbooks and romantic novels, did not).

\section{Discussion}

\subsection{Do Scents Affect Actual Customer Behavior in Retail Stores?}

Situated in the context of a growing interest in the field of aromachology, this paper has presented a systematic review of the available literature documenting the effects of using scents to create better customer experiences and affect their in-store behavior. Despite promising results from laboratory and controlled environment studies, suggesting that the addition of scents may affect product and store evaluations positively [27], the complexity and highly context-dependent nature of the sense of smell do not guarantee results will translate to actual retail environments. In fact, evidence from actual retail environments is remarkably limited, which only 20 studies meeting the inclusion criterion. This number is remarkably low in light of the fact that the relevance of scents for customer behavior has long been recognized $[7,14]$ and that the much larger number of laboratorybased studies published within the same period. This indicates that the application of aromachology in actual retail environments is still an under-researched area. This might possibly be due to practical difficulties in setting up field studies which require, on the one hand, researchers to step out of their familiar habits and, on the other, cooperative store managers interested and willing to let the study happen and share the data with the researchers.

To date, much of the published research on the effects of aromachology has relied upon the S-O-R theoretical framework [7], the core of which suggests that a pleasant scent triggers a positive affective state in the consumer, which in turn evokes approach behaviors [28]. Another often considered framework is the thematic congruency of the scent with the store's offerings, on the premise that a match between the two is a necessary condition for an effect to occur [23,31].

While the literature offers some degree of support for both, neither the S-O-R nor the thematic congruency frameworks are consistently supported by the available data, suggesting that current theoretical explanations on the effects of scents on customer behavior may need updating. Yet, explanations beyond the notions of pleasantness and congruency were rarely considered in the literature. One exception was the study by Hermann and collaborators [29] that considered a processing fluency viewpoint, based on the work by Lévy, MacRae and Köster [50], suggesting that the effect of scents on behavior depends on the perceived complexity of the scent. The finding of that study, involving a home decor store, supported this, as they showed that, whilst keeping valence and familiarity constant, the addition of a simple scent (i.e., fewer components, easy to process) led to increased actual spending, whereas a more complex scent had no such effect. This indicates that there is still much we do not know, and that future research should, in particular, consider how scent properties other than pleasantness and congruency might influence customers' behaviors in ways that are relevant to the retail sector, and try to elucidate the causal mechanisms by which such properties might do so.

\subsection{A Roadmap for Future Research in Aromachology}

What would, then, be the most important future avenues for future research? A good starting point is to look at the shortcomings of the available literature that may explain these inconsistent results. There appears to be at least three areas that should productively be explored in future research. 
Firstly, nearly all studies have dealt with the experimental data at the aggregated level, basically by simply comparing averaged data (e.g., dwell time, sales) against a control condition. This is notwithstanding the large and growing scientific evidence pointing at substantial individual differences in odor perception-due to genetics, demographics, habits, etc. [51-56]. This variability pertains to all aspects of olfaction, such as the specific quality of the perception (how does a scent test to different consumers), its perceived intensity (how strong it will be experienced as), and its valence (is it going to be perceived as pleasant or unpleasant). For example, the aging process is known to affect odor sensitivity. Ability to perceive and identify smells peaks with early childhood and declines steadily afterwards so that, generally, older individuals can be expected to be less sensitive to odors than younger ones $[55,57]$. This may be an issue of the prevalent practice of using students for selecting scenting and pre-testing their intensity, as students are generally young individuals whose olfactory functioning may not be representative of that of the end consumers (for instance, a scent may be experienced as strong by a 20-year-old person but may be very faint, or even undetectable, to a person aged 60). Likewise, men and women are known to differ in their sensitivity to smells [56,58-60], and accordingly, several studies report significant findings only when analyzing the results for men and women separately $[37,44]$. The differences are due to the individual genetic makeup, most of which are likely still unknown, that may cause individual differences in the possibility to perceive certain odors [54]. While the latter may not be relevant in the context of studies in actual retailing, phenotypical differences as a minimum have to be expected and accounted for. Finally, even if one could keep these perceptual differences invariant, there might still be differences in the importance different consumers ascribe to smells in the context of the shopping experience [61]. Therefore, the first recommendations for future research in aromachology are to move away from aggregate-level analyses in favor of analyses that account for individual differences, and secondly to ensure that the characteristics of the individuals involved in pre-testing and scent selecting match as much as possible those of the final consumers.

Secondly, nearly all papers included for review focused on varying ambient scents while minimizing variation in other store atmospherics factors. This suggests that the external validity of current research in aromachology may be limited due to the multitude of other environmental factors (such as lightning, decor, musical background, etc.) and sensory inputs that may influence the customers' in-store experience $[3,4,9,14]$. It is telling here that out of the only two studies that investigated additional factors, both reported significant interactions between in-store atmospherics. The study by Morrison and collaborators [42] found a significant two-way interaction between scent (presence vs. absence) and music (high vs. low volume) on arousal and ultimately time and money spent in the store. The study by Mattila and Wirtz also manipulated scent and music and found that when scent and music are congruent with each other, customers rated the environment significantly more positively and bought more than when these store atmospherics factors were at odds with each other [40]. Therefore, in light of these results, future research is advised to increasingly consider more complex designs when more aspects of store atmospherics can be systematically varied (on this topic, readers are also referred to the recent paper by Spence [4] who warns that "ultimately (...) only limited progress will be made in understanding the impact of ambient scent on well-being, or anything else (e.g., store sales), by considering the sense of smell in isolation from the other senses" (p. 9)). Admittedly, this is much be easier to do in a lab than in a retail environment, where store owners may object to manipulating certain aspects of the store environment. On a related note, studies should report and account for environmental changes (e.g., day-to-day weather changes) and ideally be conducted over the course of several weeks (e.g., [21,26]) to be robust against these confounders.

Lastly, a common thread across the reviewed literature is that methodological conditions appear quite poorly reported. Notably, most papers simply mentioned the commercial or lay name for the scent but their chemical composition and intensity are rarely reported. 
While several studies at least tried to estimate whether consumers were consciously aware and/or attended to any ambient scents, any reporting was exclusively based by a qualitative assessment by the experimenter. No study explicitly considered measuring the concentration of the scent, the airflow conditions, or any other aspects of air quality in the store environments (e.g., temperature, $\mathrm{CO}_{2}$ levels, volatile compounds from other sources) that would have likely affected the perception of the scents during the experimental period. Likewise, many studies did not mention the device used for diffusing scents but just referred to a generic "dispenser" or "diffuser"; only three studies [21,26,43] mentioned the specific models. Finally, while the store area was usually reported, the number and the positioning of the scent unit(s) was rarely given; thus, in many cases it was not clear whether the scent was perceived throughout the entire store or only close to target products. Taken collectively, such omissions seriously limit the reproducibility of such research and may explain inconsistencies in the results. This disregard for the chemistry of scents reflects the fact that the available literature on the effect of scents on customer behavior comes from the business field. This is in stark contrast with reporting in aromachology papers coming from other fields such as analytical chemistry (where identification and quantification of key compounds is the primary focus), and building science (where evaluation of indoor air quality follows set standards). In the latter, however, behavioral effects of scents are seldom reported or even mentioned, suggesting that collaborations across disciplines should be encouraged in future studies. In particular, considering air quality and scent concentration/intensity is needed to increase the quality and actionability of this line of research.

\section{Conclusions}

Interest in the use of scents in retail environments is growing due to the possibility to create better customer experience and potentially increase turnover. Situated within this context, this paper offers a systematic review on research in aromachology with a focus on research documenting effects on actual customer behavior in actual retail environments. The paper contributes to the literature by summarizing and assessing the available evidence pertaining to the effects of aromachology on customer behavior. As expected, the available research on actual environments (as opposed to laboratories and simulated environments) is limited, with only 20 articles meeting the inclusion criteria. While reported results are indicative of a positive effects of scent on customers' emotional states and on their in-store behavior (dwell time, product choices) and attitudes (purchase intention, intention to revisit), results were not always consistent, indicating that theoretical explanations for the effect of scents on behavior are insufficient. As additional contributions, we identified several critical issues with the available literature and provided suggestions for addressing these shortcomings. In particular, (i) focusing to a much higher degree on individual differences in olfaction (as opposed to aggregated level analyses), (ii) moving away from a narrow focus on scents to considering interactions with other atmospherics factors, and, (iii) improving the level of methodological reporting (specifically on the scents, their compositions, intensity and method of delivery) were identified as key areas for improving the quality and actionability of this line of research.

Supplementary Materials: The full list of records retrieved (whether from databases or manually) and the list of records assess for eligibility are available online at https://www.mdpi.com/article/10 .3390/app11136195/s1.

Author Contributions: Conceptualization, D.G.; methodology, D.G., B.P. and B.B.; validation, B.P. and B.B.; investigation, D.G., B.P. and B.B.; data curation, D.G.; writing—original draft preparation, D.G.; writing-review and editing, D.G., B.P. and B.B.; visualization, D.G. All authors have read and agreed to the published version of the manuscript.

Funding: This research was funded by Erasmus+ KA2 Strategic Partnerships of the European Union, grant number 2018-1-SK01-KA203-046324 (Project "Neurosmartology"), which also covered the APC.

Institutional Review Board Statement: Not applicable. 
Informed Consent Statement: Not applicable.

Data Availability Statement: Not applicable.

Conflicts of Interest: The authors declare no conflict of interest. The funders had no role in the design of the study; in the collection, analyses, or interpretation of data; in the writing of the manuscript, or in the decision to publish the results.

\section{References}

1. Ward, P.; Davies, B.J.; Kooijman, D. Olfaction and the retail environment: Examining the influence of ambient scent. Serv. Bus. 2007, 1, 295-316. [CrossRef]

2. Cao, M.T.; Duong, Q.N. Effect of Ambient Scents and Behavior Responses of Customer. Rev. Argent. Clínica Psicológica 2021, 30, 133.

3. Krishna, A. An integrative review of sensory marketing: Engaging the senses to affect perception, judgment and behavior. $J$. Consum. Psychol. 2012, 22, 332-351. [CrossRef]

4. Spence, C. Using ambient scent to enhance well-being in the multisensory built environment. Front. Psychol. 2020, 11, 598859. [CrossRef]

5. Gifford, R.; Steg, L.; Reser, J.P. Environmental psychology. In IAAP Handbook of Applied Psychology; Martin, P.R., Cheung, F.M., Knowles, M.C., Kyrios, M., Littlefield, L., Overmier, J.B., Prieto, J.M., Eds.; Wiley Blackwell: Hoboken, NJ, USA, 2011.

6. Jacoby, J. Stimulus-organism-response reconsidered: An evolutionary step in modeling (consumer) behavior. J. Consum. Psychol. 2002, 12, 51-57. [CrossRef]

7. Mehrabian, A.; Russell, J.A. The basic emotional impact of environments. Percept. Mot. Ski. 1974, 38, 283-301. [CrossRef]

8. Bakker, I.; Van Der Voordt, T.; Vink, P.; De Boon, J. Pleasure, arousal, dominance: Mehrabian and Russell revisited. Curr. Psychol. 2014, 33, 405-421. [CrossRef]

9. Lemon, K.N.; Verhoef, P.C. Understanding customer experience throughout the customer journey. J. Mark. 2016, 80, 69-96. [CrossRef]

10. Grewal, D.; Levy, M.; Kumar, V. Customer experience management in retailing: An organizing framework. J. Retail. 2009, 85, 1-14. [CrossRef]

11. Puccinelli, N.M.; Goodstein, R.C.; Grewal, D.; Price, R.; Raghubir, P.; Stewart, D. Customer experience management in retailing: Understanding the buying process. J. Retail. 2009, 85, 15-30. [CrossRef]

12. Verhoef, P.C.; Lemon, K.N.; Parasuraman, A.; Roggeveen, A.; Tsiros, M.; Schlesinger, L.A. Customer experience creation: Determinants, dynamics and management strategies. J. Retail. 2009, 85, 31-41. [CrossRef]

13. Schmitt, B. Experiential marketing. J. Mark. Manag. 1999, 15, 53-67. [CrossRef]

14. Kotler, P. Atmospherics as a marketing tool. J. Retail. 1973, 49, 48-64.

15. Roggeveen, A.L.; Grewal, D.; Schweiger, E.B. The DAST framework for retail atmospherics: The impact of in-and out-of-store retail journey touchpoints on the customer experience. J. Retail. 2020, 96, 128-137. [CrossRef]

16. Horská, E.; Sedik, P.; Bercik, J.; Krasnodebski, A.; Witczak, M.; Filipiak-Florkiewicz, A. Aromachology in food sector-aspects of consumer food products choice. Żywność Nauka Technologia Jakość 2018, 25, 33-41.

17. Wang, C.; Chen, S.L. Aromachology and its application in the textile field. Fibres Text. East. Eur. 2005, 13, 41-44.

18. Köster, E.P.; Møller, P.; Mojet, J. A “Misfit” Theory of Spontaneous Conscious Odor Perception (MITSCOP): Reflections on the role and function of odor memory in everyday life. Front. Psychol. 2014, 5, 64. [CrossRef]

19. Soars, B. Driving sales through shoppers' sense of sound, sight, smell and touch. Int. J. Retail. Distrib. Manag. 2009, 37, 286-298. [CrossRef]

20. Roschk, H.; Loureiro, S.M.C.; Breitsohl, J. Calibrating 30 years of experimental research: A meta-analysis of the atmospheric effects of music, scent, and color. J. Retail. 2017, 93, 228-240. [CrossRef]

21. Berčík, J.; Paluchová, J.; Gálová, J.; Neomániová, K.; Hladíková, L. Aroma Marketing-A Modern Marketing Phenomenon. Int. Sci. Days 2018, 586-598.

22. Jacob, C.; Stefan, J.; Guéguen, N. Ambient scent and consumer behavior: A field study in a florist's retail shop. Int. Rev. Retail. Distrib. Consum. Res. 2014, 24, 116-120. [CrossRef]

23. Gulas, C.S.; Bloch, P.H. Right under our noses: Ambient scent and consumer responses. J. Bus. Psychol. 1995, 10, 87-98. [CrossRef]

24. Parsons, A.G. Use of scent in a naturally odourless store. Int. J. Retail. Distrib. Manag. 2009, 37, 440-452. [CrossRef]

25. Helmefalk, M.; Hultén, B. Multi-sensory congruent cues in designing retail store atmosphere: Effects on shoppers' emotions and purchase behavior. J. Retail. Consum. Serv. 2017, 38, 1-11. [CrossRef]

26. Schifferstein, H.N.; Blok, S.T. The signal function of thematically (in) congruent ambient scents in a retail environment. Chem. Senses 2002, 27, 539-549. [CrossRef] [PubMed]

27. Madzharov, A.V.; Block, L.G.; Morrin, M. The cool scent of power: Effects of ambient scent on consumer preferences and choice behavior. J. Mark. 2015, 79, 83-96. [CrossRef]

28. Spangenberg, E.R.; Crowley, A.E.; Henderson, P.W. Improving the store environment: Do olfactory cues affect evaluations and behaviors? J. Mark. 1996, 60, 67-80. [CrossRef] 
29. Herrmann, A.; Zidansek, M.; Sprott, D.E.; Spangenberg, E.R. The power of simplicity: Processing fluency and the effects of olfactory cues on retail sales. J. Retail. 2013, 89, 30-43. [CrossRef]

30. Mitchell, D.J.; Kahn, B.E.; Knasko, S.C. There's something in the air: Effects of congruent or incongruent ambient odor on consumer decision making. J. Consum. Res. 1995, 22, 229-238. [CrossRef]

31. Lunardo, R. Negative effects of ambient scents on consumers' skepticism about retailer's motives. J. Retail. Consum. Serv. 2012, 19, 179-185. [CrossRef]

32. Spangenberg, E.R.; Grohmann, B.; Sprott, D.E. It's beginning to smell (and sound) a lot like Christmas: The interactive effects of ambient scent and music in a retail setting. J. Bus. Res. 2005, 58, 1583-1589. [CrossRef]

33. Biswas, D.; Labrecque, L.I.; Lehmann, D.R.; Markos, E. Making choices while smelling, tasting, and listening: The role of sensory (Dis) similarity when sequentially sampling products. J. Mark. 2014, 78, 112-126. [CrossRef]

34. Bosmans, A. Scents and sensibility: When do (in) congruent ambient scents influence product evaluations? J. Mark. 2006, 70, 32-43. [CrossRef]

35. Girona-Ruíz, D.; Cano-Lamadrid, M.; Carbonell-Barrachina, A.A.; López-Lluch, D.; Sendra, E. Aromachology related to foods, scientific lines of evidence: A Review Appl. Sci. 2021, 11, 6095.

36. Page, M.J.; McKenzie, J.E.; Bossuyt, P.M.; Boutron, I.; Hoffmann, T.C.; Mulrow, C.D.; Shamseer, L.; Tetzlaff, J.M.; Moher, D. Updating guidance for reporting systematic reviews: Development of the PRISMA 2020 statement. J. Clin. Epidemiol. 2021, 134, 103-112. [CrossRef] [PubMed]

37. Spangenberg, E.R.; Sprott, D.E.; Grohmann, B.; Tracy, D.L. Gender-congruent ambient scent influences on approach and avoidance behaviors in a retail store. J. Bus. Res. 2006, 59, 1281-1287. [CrossRef]

38. Knasko, S.C. Ambient odor and shopping behavior. Chem. Senses 1989, 14, 719.

39. Hirsch, A.R. Effects of ambient odors on slot-machine usage in a Las Vegas casino. Psychol. Mark. 1995, 12, 585-594. [CrossRef]

40. Mattila, A.S.; Wirtz, J. Congruency of scent and music as a driver of in-store evaluations and behavior. J. Retail. 2001, 77, 273-289. [CrossRef]

41. Chebat, J.C.; Michon, R. Impact of ambient odors on mall shoppers' emotions, cognition, and spending: A test of competitive causal theories. J. Bus. Res. 2003, 56, 529-539. [CrossRef]

42. Morrison, M.; Gan, S.; Dubelaar, C.; Oppewal, H. In-store music and aroma influences on shopper behavior and satisfaction. J. Bus. Res. 2011, 64, 558-564. [CrossRef]

43. Doucé, L.; Janssens, W. The presence of a pleasant ambient scent in a fashion store: The moderating role of shopping motivation and affect intensity. Environ. Behav. 2013, 45, 215-238. [CrossRef]

44. Doucé, L.; Poels, K.; Janssens, W.; De Backer, C. Smelling the books: The effect of chocolate scent on purchase-related behavior in a bookstore. J. Environ. Psychol. 2013, 36, 65-69. [CrossRef]

45. Bouzaabia, R. The effect of ambient scents on consumer responses: Consumer type and his accompaniment state as moderating variables. Int. J. Mark. Stud. 2014, 6, 155. [CrossRef]

46. Carrijo, M.C.; Minciotti, S.A.; Mazzon, J.A.; Prearo, L.C. Aromas: Influência do comportamento de compra em lojas no Brasil. Espacios 2016, 37, 23-43.

47. Errajaa, K.; Daucé, B.; Legoherel, P. Consumer reactions to olfactory congruence with brand image. J. Retail. Consum. Serv. 2020, 52, 101898. [CrossRef]

48. Dacko, S.G. Time-of-day services marketing. J. Serv. Mark. 2012, 26, 375-388. [CrossRef]

49. Murray, K.B.; Di Muro, F.; Finn, A.; Leszczyc, P.P. The effect of weather on consumer spending. J. Retail. Consum. Serv. 2010, 17, 512-520. [CrossRef]

50. Lévy, C.; MacRae, A.; Köster, E. Perceived stimulus complexity and food preference development. Acta Psychol. 2006, 123, 394-413. [CrossRef]

51. Bensafi, M.; Rouby, C. Individual differences in odor imaging ability reflect differences in olfactory and emotional perception. Chem. Senses 2007, 32, 237-244. [CrossRef]

52. Croy, I.; Buschhüter, D.; Seo, H.S.; Negoias, S.; Hummel, T. Individual significance of olfaction: Development of a questionnaire. Eur. Arch. Oto Rhino Laryngol. 2010, 267, 67-71. [CrossRef]

53. Mantel, M.; Ferdenzi, C.; Roy, J.M.; Bensafi, M. Individual differences as a key factor to uncover the neural underpinnings of hedonic and social functions of human olfaction: Current findings from PET and fMRI studies and future considerations. Brain Topogr. 2019, 32, 977-986. [CrossRef]

54. McRae, J.F.; Jaeger, S.R.; Bava, C.M.; Beresford, M.K.; Hunter, D.; Jia, Y.; Chheang, S.L.; Jin, D.; Peng, M.; Gamble, J.C.; et al. Identification of regions associated with variation in sensitivity to food-related odors in the human genome. Curr. Biol. 2013, 23, 1596-1600. [CrossRef]

55. Song, X.; Giacalone, D.; Johansen, S.M.B.; Frøst, M.B.; Bredie, W.L. Changes in orosensory perception related to aging and strategies for counteracting its influence on food preferences among older adults. Trends Food Sci. Technol. 2016, 53, 49-59. [CrossRef]

56. Dijksterhuis, G.B.; Møller, P.; Bredie, W.L.; Rasmussen, G.; Martens, M. Gender and handedness effects on hedonicity of laterally presented odours. Brain Cogn. 2002, 50, 272-281. [CrossRef] 
57. Sorokowska, A.; Schriever, V.A.; Gudziol, V.; Hummel, C.; Hähner, A.; Iannilli, E.; Sinding, C.; Aziz, M.; Seo, H.; Negoias, S.; et al. Changes of olfactory abilities in relation to age: Odor identification in more than 1400 people aged 4 to 80 years. Eur. Arch. Oto Rhino Laryngol. 2015, 272, 1937-1944. [CrossRef]

58. Koelega, H.S.; Köster, E. Some experiments on sex differences in odor perception. Ann. N. Y. Acad. Sci. 1974, 237, 234-246. [CrossRef]

59. Zucco, G.M.; Aiello, L.; Turuani, L.; Köster, E. Odor-evoked autobiographical memories: Age and gender differences along the life span. Chem. Senses 2012, 37, 179-189. [CrossRef] [PubMed]

60. Olofsson, J.K.; Nordin, S. Gender differences in chemosensory perception and event-related potentials. Chem. Senses 2004, 29, 629-637. [CrossRef] [PubMed]

61. Dörtyol, İ.T. Do consumers need to smell? Scale development and validation. J. Sens. Stud. 2021, 36, e12630. [CrossRef] 